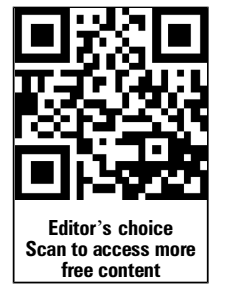

- Additional material is published online only. To view please visit the journal online (http://dx.doi.org/10.1136/ oemed-2013-101639).

1 University of Groningen, University Medical Center Groningen, Department of Epidemiology, Groningen, The Netherlands

2University of Groningen, University Medical Center Groningen, Groningen Research Institute for Asthma and COPD (GRIAC), Groningen, The Netherlands ${ }^{3}$ University of Utrecht, Institute for Risk Assessment Sciences (IRAS), Utrecht, The Netherlands

${ }^{4}$ University of Groningen, University Medical Center Groningen, Department of Pulmonology, Groningen, The Netherlands

\section{Correspondence to} J M Vonk, University of Groningen, University Medical Center Groningen, Department of Epidemiology, Groningen, Hanzeplein 1, Groningen 9700 RB, The Netherlands: J.M.Vonk@umcg.nl

Received 28 May 2013 Revised 5 September 2013

Accepted 10 September 2013

Published Online First

10 October 2013

\section{SLinked}

- http://dx.doi.org/10.1136/ oemed-2013-101876

To cite: de Jong $\mathrm{K}$ Boezen HM, Kromhout $\mathrm{H}$ et al. Occup Environ Med 2014;71:88-96

\title{
Pesticides and other occupational exposures are associated with airway obstruction: the LifeLines cohort study
}

\author{
$\mathrm{K}$ de Jong, ${ }^{1,2} \mathrm{H}$ M Boezen, ${ }^{1,2}$ H Kromhout, ${ }^{3} \mathrm{R}$ Vermeulen, ${ }^{3} \mathrm{D}$ S Postma, ${ }^{2,4}$ \\ J M Vonk, ${ }^{1,2}$ The LifeLines Cohort study
}

\begin{abstract}
Objectives Occupational exposures are important and possibly modifiable contributors to the global burden of chronic obstructive pulmonary disease (COPD). Exposure to vapours, gases, dusts and fumes (VGDF) has been associated with a two- to threefold higher COPD risk. Less is known about effects of occupational exposure to pesticides and solvents. In the current study, we assessed if VGDF, pesticides and solvents are associated with the level of lung function and the prevalence of airway obstruction in the general population.

Methods We included 11851 subjects aged 1889 years from the Lifelines cohort study. Regression models assessing associations between occupational exposures (no/low/high), level of lung function (prebronchodilator $\mathrm{FEV}_{1}, \mathrm{FEV}_{1} / \mathrm{FVC}$ ) and mild and moderate/severe airway obstruction were adjusted for sex, age, height, weight, current/ex-smoking and packyears. Additionally, we stratified by smoking status and gender and tested for interaction. A second general population cohort $(n=2364)$ was used to verify our

\section{What this article adds}

- Various studies have shown that occupational exposure to vapours, gases, dusts and fumes (VGDF) is associated with a decreased level of lung function and a higher prevalence of chronic obstructive pulmonary disease (COPD).

- This study adds to the current knowledge by showing that occupational exposure to pesticides, including herbicides and insecticides, is associated with a lower level of lung function and a higher prevalence of airway obstruction in the general population.

- Since the agricultural sector employs a large share of the population worldwide, especially in developing countries, interventions to reduce exposure levels in this occupational sector could contribute to lowering the global burden of COPD.
\end{abstract} initial findings.

Results Occupational exposure to VGDF and pesticides was associated with a lower level of $\mathrm{FEV}_{1}$ and $F E V_{1} / F V C$ and with a higher prevalence of mild and moderate/ severe airway obstruction in the two general populations investigated. There were no associations with exposure to solvents.

Conclusions Occupational exposure to both VGDF and pesticides is associated with airway obstruction in the general population.

\section{BACKGROUND}

Worldwide, millions of people suffer from chronic obstructive pulmonary disease (COPD). About 3 million people died due to COPD in 2005 . $^{1}$ The morbidity and mortality associated with the disease cause an enormous economic burden; healthcare costs of COPD in the USA alone were estimated to be US $\$ 50$ billion in $2010 .^{2}$ The global burden of COPD is still increasing and the disease is expected to become the third leading cause of death by 2030. ${ }^{3}$ Yet the cellular and molecular pathways driving COPD are still not fully understood. ${ }^{5}$ Tobacco smoking is considered to be the main risk factor for COPD, although a substantial proportion of $15-20 \%$ of all COPD cases has been attributed to occupational exposures, ${ }^{6}$ with proportions up to $30 \%$ in never smokers. ${ }^{7}$
Occupational exposure to broadly defined categories like vapours, gases, dusts and fumes and their composite measure (VGDF) have been shown in several studies to increase COPD risk two- to threefold. $^{8-11}$ Joint exposure to smoking was shown to increase the risk even 14-fold. ${ }^{9}$ Epidemiological studies investigating the effects of more specific occupational exposures, like pesticides and solvents, are scarce. Since the agricultural sector employs more than 1.1 billion workers worldwide (about 34\% of the global working force), ${ }^{12}$ adverse health effects associated with occupational exposure to pesticides can have a large public health impact. This is especially true in highly exposed populations, such as agricultural workers in developing countries who often use pesticides with insufficient protective equipment and training. ${ }^{13}$ Like pesticides, solvents are widely used agents in everyday practice, such as degreasing, cleaning and painting. Possible adverse health effects, for instance, due to their volatile and irritable properties might therefore apply to millions of people worldwide.

Because occupational exposures are common, yet also potentially modifiable contributors to the global burden of COPD, it is important to determine which occupational factors drive the 
development of COPD. Although COPD clinically manifests predominantly after age 40 , it is relevant to study early phenotypes that may be associated with the development of COPD later in life, such as decreased level of lung function and early signs of airway obstruction. In the current study, we assessed the associations of occupational exposure to gases and fumes, mineral dust, biological dust, their composite measure VGDF, pesticides in general, herbicides and insecticides specifically and various types of solvents on level of lung function and the prevalence of mild and moderate/severe airway obstruction in a general population cohort. Additionally, differential associations for never and ever smokers and men and women were investigated. A second general population cohort from the same area, that is, the Vlagtwedde-Vlaardingen cohort, was used to verify our initial findings.

\section{METHODS}

\section{Study sample}

We included individuals from the LifeLines cohort study, a multidisciplinary prospective population-based cohort study examining health and health-related behaviours of persons living in the Northern region of The Netherlands. ${ }^{14}$ Subjects were recruited via general practitioners. In the current study, we included 13301 subjects from the second data release of the LifeLines cohort. All LifeLines participants received a medical examination and questionnaires at baseline. The medical examination included prebronchodilator spirometry $\left(\mathrm{FEV}_{1}, \mathrm{FEV}_{1} /\right.$ FVC) using a Welch Allyn V.1.6.0.489, PC-based SpiroPerfect with $\mathrm{Ca}$ Workstation software. The questionnaires included questions regarding personal characteristics, smoking habits, job title and description of current or last held job.

\section{Occupational exposure}

Job title and description were coded according to the International Standard Classification of Occupations V.1988 (ISCO-88). ${ }^{15}$ These four-digit classification codes were used to estimate job-specific exposures to VGDF (subcategories gases and fumes, mineral dust and biological dust), pesticides (subcategories herbicides and insecticides) and various types of solvents (aromatic, chlorinated, other) using the ALOHA+ job exposure matrix (JEM). ${ }^{8}$ The ALOHA+ JEM classifies subjects based on the ISCO-88 job codes into no, low and high exposure categories $(0 / 1 / 2)$. In case a participant had two different jobs simultaneously, exposures of both jobs were averaged and rounded to the nearest integer $(0.5=1$ and $1.5=2)$.

\section{Statistical analysis}

Associations of the specific occupational agents with prebronchodilator level of lung function $\left(\mathrm{FEV}_{1}\right.$ and $\left.\mathrm{FEV}_{1} / \mathrm{FVC}\right)$ and mild and moderate/severe airway obstruction were assessed using linear and logistic regression adjusted for sex, age, height, weight, current/ex-smoking and packyears (log packyears+1), all at enrolment. Mild obstruction was defined as prebronchodilator $\mathrm{FEV}_{1} / \mathrm{FVC}<70 \%$. To assess associations with more severe obstruction, we defined moderate/severe obstruction as having prebronchodilator $\mathrm{FEV}_{1} / \mathrm{FVC}<70 \%$ and $\mathrm{FEV}_{1}<80 \%$ predicted and no obstruction as having prebronchodilator $\mathrm{FEV}_{1} /$ FVC $\geq 70 \%$ and $\mathrm{FEV}_{1} \geq 80 \%$ predicted. ${ }^{16}$ Subjects with mild obstruction (prebronchodilator $\quad \mathrm{FEV}_{1} / \mathrm{FVC}<70 \%$ and $\mathrm{FEV}_{1} \geq 80 \%$ predicted) or with possible other pathology, like restrictive lung disease (prebronchodilator $\mathrm{FEV}_{1} / \mathrm{FVC} \geq 70 \%$ and $\mathrm{FEV}_{1}<80 \%$ predicted) were excluded from this analysis (LifeLines $\mathrm{n}=1517(13 \%)$ and Vlagtwedde-Vlaardingen $\mathrm{n}=436$ $(18 \%))$.
Because of substantial co-exposure between the specific occupational agents (see online supplementary table S1), we additionally adjusted the models with exposure to VGDF, gases, fumes, mineral dust and biological dust for exposure to pesticides, whereas the models with exposure to pesticides, herbicides and insecticides were additionally adjusted for exposure to VGDF. Since subjects with high exposure to pesticides always were highly exposed to VGDF, it was not possible to formally test for interaction between the two exposures.

In additional analyses, we stratified by smoking status (never/ ever) and by gender. A subject was defined as ever smoker when being either a current or an ex-smoker. Interactions between the exposures and smoking or gender were tested by including their interaction terms in the unstratified models (ie, low exposure $x$ ever smoker; high exposure $\times$ ever smoker; low exposure $\times$ gender and high exposure $\times$ gender, respectively). p Values $<0.05$ were considered statistically significant. All analyses were performed in SPSS V.20.0 (IBM Corporation, USA).

\section{Verification cohort}

Subjects who participated in the last survey (1989/1990) of the Vlagtwedde-Vlaardingen cohort were used to verify our initial findings (table 1). The Vlagtwedde-Vlaardingen cohort is a general population-based cohort that has started in 1965 and has been followed for 25 years. During each survey, information was collected by questionnaires and spirometry, using a slow inspiratory manoeuvre, was performed with a water-sealed spirometer (Lode Instruments, Groningen, the Netherlands). We used current job, or the last held job in case of current

Table 1 Characteristics of the included study populations from the LifeLines and Vlagtwedde-Vlaardingen cohorts

\begin{tabular}{|c|c|c|}
\hline & LifeLines & Vlagtwedde-Vlaardingen \\
\hline $\mathrm{N}$ with non-missing data & 11851 & 2364 \\
\hline Men, $\mathrm{n}(\%)$ & $4878(41)$ & $1265(54)$ \\
\hline $\begin{array}{l}\text { Age (years), median (minimum- } \\
\text { maximum) }\end{array}$ & 47 (18-89) & $52(35-79)$ \\
\hline \multicolumn{3}{|l|}{ Smoking status } \\
\hline Never, n (\%) & $5091(43)$ & 760 (32) \\
\hline Ever, n (\%) & $6760(57)$ & $1604(68)$ \\
\hline Ex, n (\%) & $4267(36)$ & $753(32)$ \\
\hline Current, n (\%) & $2493(21)$ & $851(36)$ \\
\hline $\begin{array}{l}\text { Packyears in ever smokers, median } \\
\text { (25-75th centiles) }\end{array}$ & $10(5-19)$ & $19(9-31)$ \\
\hline \multicolumn{3}{|l|}{ Lung function, mean (SD) } \\
\hline $\mathrm{FEV}_{1} \%$ predicted $^{*}$ & $103(14)$ & $93(16)$ \\
\hline $\mathrm{FEV}_{1} / \mathrm{FVC}(\%) \dagger$ & $76(7)$ & $74(9)$ \\
\hline \multicolumn{3}{|l|}{ Airway obstruction } \\
\hline No $\left(\mathrm{FEV}_{1} / \mathrm{FVC} \geq 70 \%\right), \mathrm{n}(\%)$ & $10097(85)$ & $1725(73)$ \\
\hline $\mathrm{FEV}_{1} \%$ predicted, mean (SD) & $105(13)$ & $98(13)$ \\
\hline Mild (FEV $1 / F V C<70 \%), n(\%)$ & $1754(15)$ & $639(27)$ \\
\hline $\mathrm{FEV}_{1} \%$ predicted, mean (SD) & 89 (15) & 79 (16) \\
\hline Moderate/severeł, n (\%) & $458(4)$ & $314(13)$ \\
\hline $\mathrm{FEV}_{1} \%$ predicted, mean (SD) & $70(9)$ & $67(11)$ \\
\hline
\end{tabular}

${ }^{*} \mathrm{FEV}_{1} \%$ predicted is $\mathrm{FEV}_{1}$ as percentage predicted based on reference equations by Quanjer et al. ${ }^{16}$

tVlagtwedde-Vlaardingen: $\mathrm{FEV}_{1} / \mathrm{IVC}$.

¥Moderate/severe obstruction: subjects with moderate/severe

obstruction=prebronchodilator $\mathrm{FEV}_{1} / \mathrm{FVC}<70 \%$ and $\mathrm{FEV}_{1}<80 \%$, subjects without

obstruction=prebronchodilator $\mathrm{FEV}_{1} / \mathrm{FVC} \geq 70 \%$ and $\mathrm{FEV}_{1} \geq 80 \%$. Subjects with mild obstruction (prebronchodilator $\mathrm{FEV}_{1} / \mathrm{FVC}<70 \%$ and $\mathrm{FEV}_{1} \geq 80 \%$ predicted) or prebronchodilator $\mathrm{FEV}_{1} / \mathrm{FVC} \geq 70 \%$ and $\mathrm{FEV}_{1}<80 \%$ predicted were excluded from this analysis (LifeLines $n=1517(13 \%)$ and Vlagtwedde-Vlaardingen $n=436(18 \%))$. 
unemployment (eg, retirement) that was reported at the last survey (1989/1990). Job coding, exposure assessment and statistical analyses were performed according to the same protocol as in the LifeLines cohort.

\section{RESULTS \\ Characteristics of the LifeLines study population and prevalence of exposure}

From the initial LifeLines sample of 13301 subjects, a total of 1450 subjects were excluded because of insufficient quality of spirometry $(\mathrm{n}=725)$ or lacking information on covariates $(n=725)$. Characteristics of the included and excluded subjects can be found in the online supplementary table S2. Table 1 shows the characteristics of 11851 LifeLines participants who were included in the final sample. High level of occupational exposure (category 2) to the broadly defined category VGDF was quite common (11\%) (for an overview of the type of workers with high exposure to VGDF, see online supplementary table S3). Only a small number of people had high exposure to pesticides (1\%) (for numbers and prevalence of each exposure, see table 2). Men were more often exposed and had more often high exposure (category 2) than women.

\section{VGDF exposure}

Occupational exposure to VGDF in general (figure 1A), and the subcategory gases and fumes, was associated with a lower level of $\mathrm{FEV}_{1}$ (table 2) and $\mathrm{FEV}_{1} / \mathrm{FVC}$ (table 3 ) and a higher prevalence of mild and moderate/severe airway obstruction (table 4), with the strongest associations for the groups with high exposure. The negative association of high exposure to VGDF and gases and fumes with level of $\mathrm{FEV}_{1}$ was significantly stronger in ever smokers than never smokers (ie, $\mathrm{p}$ values for interaction $<0.05$ ), whereas the associations with $\mathrm{FEV}_{1} / \mathrm{FVC}$ were not significantly different between never and ever smokers. Exposure to mineral dust was associated with a lower level of $\mathrm{FEV}_{1}$ and with a higher prevalence of mild and moderate/severe airway obstruction, whereas the association with level of $\mathrm{FEV}_{1} / \mathrm{FVC}$ was less consistent. The association between low exposure to mineral dust and level of $\mathrm{FEV}_{1}$ was significantly stronger in ever smokers compared with never smokers. Exposure to biological dust was not significantly associated with level of $\mathrm{FEV}_{1}$ (table 2) and $\mathrm{FEV}_{1} / \mathrm{FVC}$ (table 3 ) or airway obstruction (table 4). There were no significant differences in the associations between occupational exposures and level of $\mathrm{FEV}_{1}$ or $\mathrm{FEV}_{1} / \mathrm{FVC}$ between men and women.

\section{Pesticide exposure}

Exposures to pesticides (figure 1B) and the subcategories herbicides and insecticides were associated with significantly lower levels of $\mathrm{FEV}_{1}$ in an exposure-dependent way (table 2). Exposure to pesticides was also associated with a lower level of $\mathrm{FEV}_{1} / \mathrm{FVC}$ (table 3 ) and a higher prevalence of mild and moderate/severe airway obstruction (table 4), yet these associations only reached significance for exposure to herbicides. The association between low exposure to pesticides and level of $\mathrm{FEV}_{1}$ was significantly stronger in the ever smokers compared with the never smokers ( $p$ value for interaction $<0.05$ ). There was no difference between ever smokers and never smokers for high exposure to pesticides. Associations of exposure to pesticides with $\mathrm{FEV}_{1} / \mathrm{FVC}$ were not significantly different between ever smokers and never smokers or men and women.

\section{Solvent exposure}

Low exposure to aromatic solvents was associated with a marginally lower level of $\mathrm{FEV}_{1} / \mathrm{FVC}$ (see online supplementary table S4) and a higher prevalence of mild airway obstruction (see online supplementary table S5). There were no associations between low exposure to aromatic solvents and level of $\mathrm{FEV}_{1}$ or moderate/severe airway obstruction and no associations between high exposure and level of $\mathrm{FEV}_{1}, \mathrm{FEV}_{1} / \mathrm{FVC}$ or prevalence of airway obstruction. There were no associations between exposure to chlorinated and other types of solvents and level of $\mathrm{FEV}_{1}, \mathrm{FEV}_{1} / \mathrm{FVC}$ (see online supplementary table S4) or prevalence of airway obstruction (see online supplementary table S5).

\section{Verification of associations in the Vlagtwedde-Vlaardingen cohort}

Full data on all covariates were available for 2364 subjects participating in the last survey of the Vlagtwedde-Vlaardingen cohort. These subjects were slightly older, more often men, more often ever smokers, had a lower level of lung function and more often had airway obstruction than subjects from the LifeLines cohort (table 1). Exposure to high levels of VGDF (33\%) and pesticides $(12 \%)$ was more common than in the LifeLines cohort (for the prevalence of all exposures in the Vlagtwedde-Vlaardingen cohort, see online supplementary table S6).

The associations of VGDF and the subcategory gases and fumes with level of $\mathrm{FEV}_{1}$ (see online supplementary table S6), $\mathrm{FEV}_{1} / \mathrm{FVC}$ (see online supplementary table S7) and the prevalence of mild and moderate/severe airway obstruction (table 4) in the Vlagtwedde-Vlaardingen cohort were comparable with the LifeLines cohort. Contrary to findings in the LifeLines cohort, the associations with level of lung function were not stronger in the ever smokers. Moreover, the associations of exposure to mineral dust with level of $\mathrm{FEV}_{1}$ and prevalence of airway obstruction could not be replicated.

Associations between occupational exposure to pesticides and a lower level of $\mathrm{FEV}_{1} / \mathrm{FVC}$ (see online supplementary table S7) and a higher prevalence of mild and moderate/severe airway obstruction (table 4) in the Vlagtwedde-Vlaardingen cohort were comparable with associations in the LifeLines cohort. The negative associations between exposure to pesticides and level of $\mathrm{FEV}_{1}$ were replicated in the ever smokers only (see online supplementary table S6).

The marginal association between low exposure to aromatic solvents and a lower level of $\mathrm{FEV}_{1} / \mathrm{FVC}$ in the LifeLines cohort was replicated in the Vlagtwedde-Vlaardingen cohort (see online supplementary table S8).

\section{DISCUSSION}

\section{Main findings}

Occupational exposure to VGDF and pesticides was associated with a lower level of $\mathrm{FEV}_{1}$ and $\mathrm{FEV}_{1} / \mathrm{FVC}$ and a higher prevalence of airway obstruction. There were no consistent associations with exposure to solvents.

\section{Results in relation to other studies}

In line with previous findings in the literature, we showed that occupational exposure to VGDF was clearly associated with lower levels of $\mathrm{FEV}_{1}$ and $\mathrm{FEV}_{1} / \mathrm{FVC}$ as well as with a higher prevalence of airway obstruction in both our general populations investigated. ${ }^{8-11} 17 \quad 18$ Associations in our study were exposure dependent. In the European Community Respiratory Health Survey (ECRHS) study, high exposure to VGDF was associated with a $61 \mathrm{~mL}$ lower $\mathrm{FEV}_{1}$ in current smokers, 
Table 2 Associations between occupational exposures and level of $\mathrm{FEV}_{1}(\mathrm{~mL})$ in the LifeLines cohort

\begin{tabular}{|c|c|c|c|c|c|c|c|c|c|c|}
\hline \multicolumn{5}{|l|}{ LifeLines } & \multicolumn{6}{|l|}{$\mathrm{FEV}_{1}(\mathrm{~mL})$} \\
\hline & All & & Never smokers & & Ever smokers & & Men & & Women & \\
\hline Exposuret & b $(95 \% \mathrm{Cl})$ & $\mathrm{N}(\%)$ & b $(95 \% \mathrm{Cl})$ & $\mathrm{N}$ & b $(95 \% \mathrm{Cl})$ & $\mathrm{N}$ & b $(95 \% \mathrm{Cl})$ & N & b $(95 \% \mathrm{Cl})$ & $\mathrm{N}$ \\
\hline \multicolumn{11}{|l|}{ VGDF } \\
\hline Non-exposed & Ref & $6534(55)$ & Ref & 2910 & Ref & 3624 & Ref & 2580 & Ref & 3954 \\
\hline Low & $-9(-28$ to 9$)$ & 3985 (34) & $-4(-31$ to 23$)$ & 1633 & $-14(-38$ to 11$)$ & 2352 & $-23(-61$ to 15$)$ & 1167 & $-5(-23$ to 13$)$ & 2818 \\
\hline High & $-83(-115 \text { to }-51)^{* * *}$ & $1332(11)$ & $-65(-114 \text { to }-16)^{* *}$ & 548 ‡ & $-96(-138 \text { to }-55)^{* * *}$ & 784 & $-83(-125 \text { to }-40)^{* * *}$ & 1131 & -65 (-138 to 8) & 201 \\
\hline \multicolumn{11}{|l|}{ Gases/fumes } \\
\hline Non-exposed & Ref & 7007 (59) & Ref & 3154 & Ref & 3853 & Ref & 2702 & Ref & 4305 \\
\hline Low & $-13(-31$ to 5$)$ & 4159 (35) & $-4(-31$ to 23$)$ & 1692 & $-21(-45$ to 4$)$ & 2467 & $-34(-71$ to 2$)$ & $1566 \ddagger$ & $-3(-22$ to 16$)$ & 2593 \\
\hline High & $-73(-110 \text { to }-35)^{* * *}$ & $685(6)$ & -35 (-95 to 24$)$ & $245 \ddagger$ & $-96(-144 \text { to }-47)^{* \text { ** }}$ & 440 & $-76(-125 \text { to }-27)^{* *}$ & 610 & $-36(-122$ to 51$)$ & 75 \\
\hline \multicolumn{11}{|l|}{ Mineral dust } \\
\hline Non-exposed & Ref & 9389 (79) & Ref & 4121 & Ref & 5268 & Ref & 3366 & Ref & 6023 \\
\hline Low & $-28(-52 \text { to }-5)^{*}$ & 1924 (16) & -9 (-45 to 26$)$ & $754 \ddagger$ & $-45(-75 \text { to }-14)^{* *}$ & 1170 & $-56(-96 \text { to }-17)^{* *}$ & 1037 ‡ & -4 (-31 to 24$)$ & 887 \\
\hline High & $-65(-111 \text { to }-18)^{* *}$ & $538(5)$ & $-79(-151 \text { to }-7)^{*}$ & 216 & $-57(-118$ to 4$)$ & 322 & $-65(-125 \text { to }-5)^{*}$ & 475 & $-69(-186$ to 48$)$ & 63 \\
\hline \multicolumn{11}{|l|}{ Biological dust } \\
\hline Non-exposed & Ref & 8127 (69) & Ref & 3514 & Ref & 4613 & Ref & 3729 & Ref & 4398 \\
\hline Low & $-7(-26$ to 13$)$ & $3256(28)$ & $-10(-39$ to 18$)$ & 1355 & $-4(-30$ to 22$)$ & 1901 & $-3(-47$ to 41$)$ & 783 & $-11(-30$ to 8$)$ & 2473 \\
\hline High & $-35(-85$ to 16$)$ & $468(4)$ & $-7(-80$ to 65$)$ & $222 \ddagger$ & $-58(-128$ to 12$)$ & 246 & $-46(-113$ to 22$)$ & 366 & $29(-75$ to 133$)$ & 102 \\
\hline \multicolumn{11}{|l|}{ All pesticides } \\
\hline Non-exposed & Ref & 11369 (96) & Ref & 4844 & Ref & 6525 & Ref & 4523 & Ref & 6846 \\
\hline Low & $-51(-102 \text { to } 0)^{*}$ & $370(3)$ & $-19(-88$ to 50$)$ & $192 \ddagger$ & $-91(-165 \text { to }-17)^{*}$ & 178 & $-54(-127$ to 18$)$ & 264 & $-26(-103$ to 50$)$ & 106 \\
\hline High & $-113(-201 \text { to }-25)^{*}$ & $112(1)$ & $-102(-223$ to 20$)$ & 55 & $-127(-253 \text { to }-1)^{*}$ & 57 & $-94(-213$ to 24$)$ & 91 & $-110(-274$ to 54$)$ & 21 \\
\hline \multicolumn{11}{|l|}{ Herbicides } \\
\hline Non-exposed & Ref & 11680 (99) & Ref & 5008 & Ref & 6672 & Ref & 4746 & Ref & 6934 \\
\hline Low & $-59(-140$ to 22$)$ & $132(1)$ & $-34(-146$ to 77$)$ & 64 & $-82(-197$ to 33$)$ & 68 & $-38(-148$ to 72$)$ & 104 & $-81(-223$ to 61$)$ & 28 \\
\hline High & $-204(-350 \text { to }-58)^{* *}$ & $39(0.3)$ & $-175(-376$ to 26$)$ & 19 & $-241(-450 \text { to }-32)^{*}$ & 20 & $-172(-379$ to 35$)$ & 28 & $-191(-416$ to 34$)$ & 11 \\
\hline \multicolumn{11}{|l|}{ Insecticides } \\
\hline Non-exposed & Ref & $11425(96)$ & Ref & 4870 & Ref & 6555 & Ref & 4576 & Ref & 6849 \\
\hline Low & $-50(-105$ to 5$)$ & $315(3)$ & $-1(-75$ to 73$)$ & 166 & $-109(-190 \text { to }-28)^{* *}$ & 149 & $-56(-137$ to 25$)$ & 212 & -21 (-99 to 56$)$ & 103 \\
\hline High & $-109(-197 \text { to }-21)^{*}$ & $111(1)$ & -98 ( -219 to 24$)$ & 55 & $-124(-251$ to 4$)$ & 56 & -91 ( -210 to 28$)$ & 90 & $-109(-273$ to 55$)$ & 21 \\
\hline
\end{tabular}

Statistically significant associations are depicted in bold.

Associations between occupational exposures and level of FEV ${ }_{1}(\mathrm{~mL})$ using linear regression with adjustment for sex, age, height, weight, current, ex-smoking and (log) packyears smoked in the Lifelines cohort study. The analyses with VGDF, gases, fumes, mineral dust and biological dust were additionally adjusted for pesticide exposure, whereas the analyses with pesticides, herbicides and insecticides were additionally adjusted for VGDF exposure. Stratification according to smoking status (never/ ever) and gender is shown.

${ }_{* * 0}^{*} p<0.05$.

$* * * 0<0.001$

TOccupational exposures (no/low/high) were estimated based on job title and function using the ALOHA+job exposure matrix. Non-exposed subjects were assigned as reference category (Ref).

¥Significantly different for never and ever smokers or men and women (ie, p value for interaction $<0.05$ ).

FSignificantly different for never and ever
VGDF, vapours, gases, dust and fumes. 

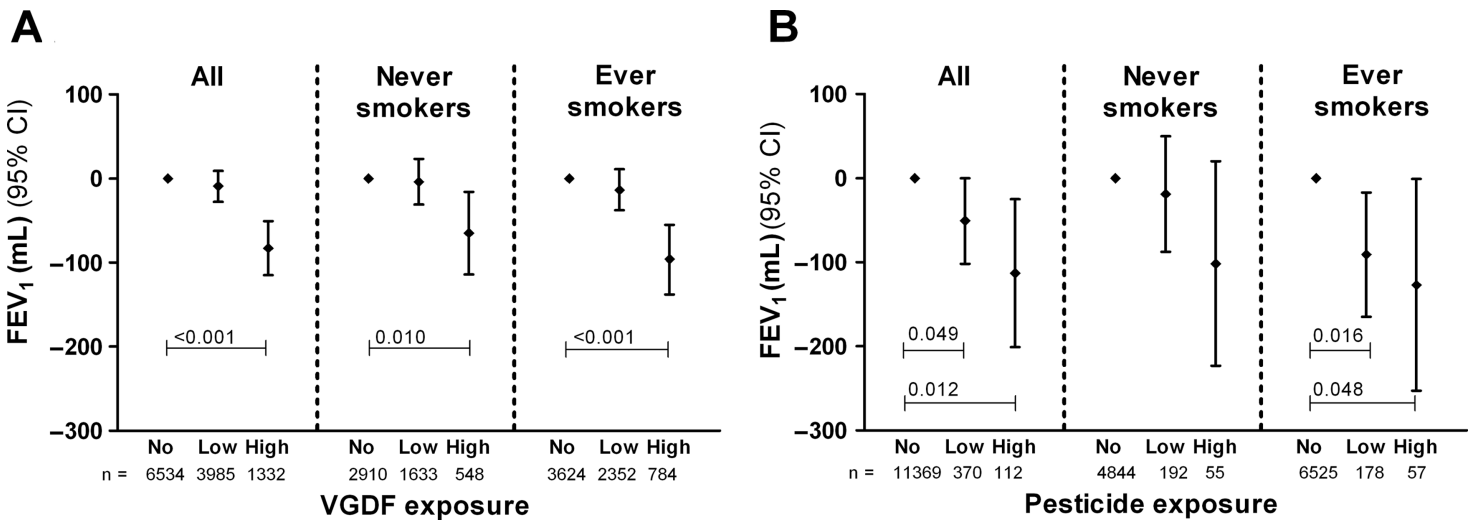

Figure 1 The association between occupational exposure (no/low/high) to vapours, gases, dust and fumes (VGDF) (A) and to pesticides (B) and the level of $\mathrm{FEV}_{1}$ in the whole group and stratified by smoking status (never/ever).

whereas in our study we found a $96 \mathrm{~mL}$ lower $\mathrm{FEV}_{1}$ associated with high exposure to VGDF in ever smokers. Contrary to our findings, there was no association in never smokers from the ECRHS study. ${ }^{18}$ These differences might relate to the lower average age of the ECRHS population, which consisted mainly of young adults (range 20-44 years) compared with LifeLines (18-89 years). We found consistent associations with the subcategory gases and fumes in both cohorts. The association between exposure to mineral dust, lower level of $\mathrm{FEV}_{1}$ and higher prevalence of airway obstruction was present in the LifeLines cohort but not in the Vlagtwedde-Vlaardingen cohort. This might be due to differences between both cohorts, for example, regarding exposure intensity within the exposed. In general, findings in both cohorts confirm that occupational exposure to VGDF is associated with lower levels of lung function and a higher prevalence of airway obstruction.

To our knowledge, this is the first study showing associations of exposure to pesticides, including herbicides and insecticides, with a lower level of lung function and a higher prevalence of airway obstruction in two general populations from a westernised country. Exposure to specific types of pesticides has been associated with chronic bronchitis in US farmers ${ }^{19}$ and their spouses $^{20}$ enrolled in the Agricultural Health Study. To date, few studies showed that pesticide exposed farming or manufacturing workers had lower lung function levels than non-exposed workers, ${ }^{21}$ whereas others found no associations. ${ }^{22-24}$ These studies were all performed in specific subgroups, like plantation or pesticide factory workers, in developing countries. In contrast, we investigated a general population and occupational exposure to pesticides appeared to be associated with a significant loss of $\mathrm{FEV}_{1}$ and $\mathrm{FEV}_{1} / \mathrm{FVC}$, especially in smokers. For example, if mean lifetime exposure to pesticides would be about 20 years, a total loss of $200 \mathrm{~mL} \mathrm{FEV}_{1}$ for exposure to herbicides implies a loss of $10 \mathrm{~mL}$ per year. This corresponds to smoking of one package of cigarettes per day for 1 year, which was associated with an $11 \mathrm{~mL}$ loss of $\mathrm{FEV}_{1}$ per packyear smoked in our study.

Moreover, we showed that workers exposed to pesticides had an almost 2 times higher prevalence of moderate/severe airway obstruction than non-exposed workers. These associations were similar in both populations investigated. Subjects who were highly exposed to pesticides included gardeners, field-grown crop and vegetable growers and mixed crop and animal farmers. Associations in the LifeLines sample remained present when each of these three main occupational groups with high exposure to pesticides was excluded one by one, yet associations were clearly strongest in the field crop and vegetable growers. Between 1985 and today, about 90\% of agriculture in the Northern Dutch Provinces consisted of arable crops, on average $\sim 30 \%$ potatoes, $\sim 30 \%$ cereals, $\sim 15 \%$ beets and $\sim 15 \%$ maize (personal communication, M Brouwer, University of Utrecht). In terms of pesticide use, this means that mainly herbicides have been applied (cereals, beets, maize) and substantial fungicide use on potatoes (mainly dithiocarbamate fungicides) (for more specific information, see online supplementary file: additional information 1). In a global perspective, the agricultural sector employs a large share of the population worldwide, especially in developing countries where workers often use pesticides with insufficient protective equipment and training. ${ }^{13}$ Therefore, interventions to reduce exposure levels in this occupational sector could contribute to lowering the global burden of COPD.

\section{Strengths and limitations}

A limitation of this study was the incomplete occupational history within the LifeLines cohort study. However, since we believe that people are more likely to move from so-called bluecollar to white-collar occupations, for example, due to symptoms or objective disease, than the other way around, we hypothesise that with using current or last held job we rather have underestimated than overestimated the association between occupational exposures and lung function level. Second, we have used prebronchodilator spirometry to define airway obstruction and assessed associations in a sample, including subjects below 40 years of age. However, the associations did not change when we restricted our analysis to subjects aged 40 years and older. When the analyses on level of lung function were stratified by age ( $<40$ and $\geq 40$ years), we found that the association between exposure to pesticides and level of lung function remained only in the group with older age, which may be due to a longer time of exposure or the use of better protective equipment nowadays. The associations between exposure to VGDF and level of lung function remained in both age groups. Finally, we have assessed associations with actual mL-values $\mathrm{FEV}_{1}$, with extensive adjustment for individual predictors of lung function level rather than percentage predicted values using an external reference population. However, associations did not change when we used $\mathrm{FEV}_{1}$ as percentage predicted instead of the actual level of $\mathrm{FEV}_{1}$ in $\mathrm{mL}$.

Because of the considerable sample size and inclusion of subjects from rural parts of the Netherlands, we were able to assess associations of exposures with low prevalence, like pesticides, and additionally the interaction between occupational exposures 
Table 3 Associations between occupational exposures and level of $\mathrm{FEV}_{1} / \mathrm{FVC}(\%)$ in the LifeLines cohort

\begin{tabular}{|c|c|c|c|c|c|c|c|c|c|c|}
\hline \multicolumn{5}{|l|}{ LifeLines } & \multicolumn{6}{|l|}{$\mathrm{FEV}_{1} / \mathrm{FVC}(\%)$} \\
\hline & All & & Never smokers & & Ever smokers & & Men & & Women & \\
\hline Exposuret & b $(95 \% \mathrm{Cl})$ & N (\%) & b $(95 \% \mathrm{Cl})$ & N & b $(95 \% \mathrm{Cl})$ & N & b $(95 \% \mathrm{Cl})$ & N & b $(95 \% \mathrm{Cl})$ & N \\
\hline \multicolumn{11}{|l|}{ VGDF } \\
\hline Non-exposed & Ref & $6534(55)$ & Ref & 2910 & Ref & 3624 & Ref & 2580 & Ref & 3954 \\
\hline Low & $-0.3(-0.6 \text { to }-0.1)^{\star * *}$ & 3985 (34) & $-0.1(-0.5$ to 0.3$)$ & 1633 & $-0.5(-0.9 \text { to }-0.2)^{* *}$ & 2352 & $-0.5(-0.9$ to 0$)$ & 1167 & $-0.3(-0.6$ to 0$)$ & 2818 \\
\hline High & $-0.7(-1.2 \text { to }-0.3)^{\star *}$ & $1332(11)$ & $-0.6(-1.3$ to 0.1$)$ & 548 & $-0.8(-1.4 \text { to }-0.2)^{* *}$ & 784 & $-0.8(-1.3 \text { to }-0.2)^{\star *}$ & 1131 & $-0.7(-1.9$ to 0.5$)$ & 201 \\
\hline \multicolumn{11}{|l|}{ Gases/fumes } \\
\hline Non-exposed & Ref & 7007 (59) & Ref & 3154 & Ref & 3853 & Ref & 2702 & Ref & 4305 \\
\hline Low & $-0.4(-0.6 \text { to }-0.1)^{\star *}$ & 4159 (35) & $-0.1(-0.5$ to 0.2$)$ & 1692 & $-0.5(-0.9 \text { to }-0.2)^{* *}$ & 2467 & $-0.4(-0.9$ to 0$)$ & 1566 & $-0.3(-0.6 \text { to } 0)^{*}$ & 2593 \\
\hline High & $-0.7(-1.3 \text { to }-0.2)^{\star *}$ & $685(6)$ & $-0.6(-1.4$ to 0.3$)$ & 245 & $-0.8(-1.6 \text { to }-0.1)^{*}$ & 440 & $-0.8(-1.4 \text { to }-0.1)^{*}$ & 610 & $-0.6(-2.1$ to 0.8$)$ & 75 \\
\hline \multicolumn{11}{|l|}{ Mineral dust } \\
\hline Non-exposed & Ref & $9389(79)$ & Ref & 4121 & Ref & 5268 & Ref & 3366 & Ref & 6023 \\
\hline Low & $-0.4(-0.8 \text { to }-0.1)^{*}$ & $1924(16)$ & $-0.4(-0.9$ to 0.1$)$ & 754 & $-0.5(-1.0 \text { to }-0.1)^{*}$ & 1170 & $-0.6(-1.1 \text { to }-0.1)^{*}$ & 1037 & $-0.2(-0.7$ to 0.2$)$ & 887 \\
\hline High & $-0.1(-0.8$ to 0.5$)$ & $538(5)$ & $-0.3(-1.3$ to 0.7$)$ & 216 & $-0.1(-0.9$ to 0.8$)$ & 322 & $-0.4(-1.1$ to 0.4$)$ & 475 & $1.2(-0.7$ to 3.2$)$ & 63 \\
\hline \multicolumn{11}{|l|}{ Biological dust } \\
\hline Non-exposed & Ref & $8127(69)$ & Ref & 3514 & Ref & 4613 & Ref & 3729 & Ref & 4398 \\
\hline Low & $-0.1(-0.4$ to 0.2$)$ & $3256(28)$ & $0.1(-0.3$ to 0.5$)$ & 1355 & $-0.2(-0.6$ to 0.1$)$ & 1901 & $0.4(-0.2$ to 1.0$)$ & $783 \ddagger$ & $-0.3(-0.6$ to 0$)$ & 2473 \\
\hline High & $-0.2(-0.9$ to 0.5$)$ & $468(4)$ & $-0.3(-1.3$ to 0.7$)$ & 222 & $-0.1(-1.1$ to 0.9$)$ & 246 & $-0.2(-1.0$ to 0.7$)$ & 366 & 0.6 (-1.1 to 2.4$)$ & 102 \\
\hline \multicolumn{11}{|l|}{ All pesticides } \\
\hline Non-exposed & Ref & 11369 (96) & Ref & 4844 & Ref & 6525 & Ref & 4523 & Ref & 6846 \\
\hline Low & $-0.4(-1.1$ to 0.3$)$ & $370(3)$ & $-0.5(-1.5$ to 0.5$)$ & 192 & $-0.3(-1.4$ to 0.7$)$ & 178 & $-0.3(-1.3$ to 0.6$)$ & 264 & $-0.5(-1.7$ to 0.8$)$ & 106 \\
\hline High & $-1.1(-2.3$ to 0.2$)$ & $112(1)$ & $-0.7(-2.4$ to 1.0$)$ & 55 & $-1.4(-3.3$ to 0.4$)$ & 57 & $-0.7(-2.2$ to 0.8$)$ & 91 & $-2.5(-5.2$ to 0.2$)$ & 21 \\
\hline \multicolumn{11}{|l|}{ Herbicides } \\
\hline Non-exposed & Ref & $11680(99)$ & Ref & 5008 & Ref & 6672 & Ref & 4746 & Ref & 6934 \\
\hline Low & $-0.3(-1.5$ to 0.8$)$ & $132(1)$ & $0.3(-1.3$ to 1.8$)$ & 64 & $-0.9(-2.6$ to 0.8$)$ & 68 & $0(-1.4$ to 1.4$)$ & 104 & $-1.5(-3.8$ to 0.9$)$ & 28 \\
\hline High & $-2.8(-4.8 \text { to }-0.7)^{\star *}$ & $39(0.3)$ & $-2.7(-5.5$ to 0.1$)$ & 19 & $-2.7(-5.7$ to 0.3$)$ & 20 & $-2.9(-5.5 \text { to }-0.3)^{*}$ & 28 & $-2.4(-6.1$ to 1.4$)$ & 11 \\
\hline \multicolumn{11}{|l|}{ Insecticides } \\
\hline Non-exposed & Ref & 11425 (96) & Ref & 4870 & Ref & 6555 & Ref & 4576 & Ref & 6849 \\
\hline Low & $-0.4(-1.2$ to 0.3$)$ & $315(3)$ & $-0.5(-1.6$ to 0.5$)$ & 166 & $-0.4(-1.6$ to 0.8$)$ & 149 & $-0.4(-1.4$ to 0.6$)$ & 212 & $-0.5(-1.8$ to 0.8$)$ & 103 \\
\hline High & $-1.1(-2.3$ to 0.2$)$ & $111(1)$ & $-0.7(-2.4$ to 1.0$)$ & 55 & $-1.5(-3.3$ to 0.4$)$ & 56 & $-0.7(-2.2$ to 0.8$)$ & 90 & $-2.5(-5.2$ to 0.2$)$ & 21 \\
\hline
\end{tabular}

Statistically significant associations are depicted in bold.

Associations between occupational exposures and level of FEV $1 / F V C$ (\%) using linear regression with adjustment for sex, age, height, weight, current, ex-smoking and (log) packyears smoked in the Lifelines cohort study. The analyses with VGDF, gases, fumes, mineral dust and biological dust were additionally adjusted for pesticide exposure, whereas the analyses with pesticides, herbicides and insecticides were additionally adjusted for VGDF exposure. Stratification according to smoking status (never/ ever) and gender is shown.

${ }^{*} \mathrm{p}<0.05$

$* * \mathrm{p}<0.01$
$* * * \mathrm{p}<0.001$

tOccupational exposures (no/low/high) were estimated based on job title and function using the ALOHA+job exposure matrix. Non-exposed subjects were assigned as reference category (Ref).

ҰSignificantly different for men and women (ie, $\mathrm{p}$ value for interaction $<0.05$ ).

VGDF, vapours, gases, dust and fumes. 
Table 4 Associations between occupational exposures and airway obstruction in the LifeLines and Vlagtwedde-Vlaardingen cohorts

\begin{tabular}{|c|c|c|c|c|c|c|c|c|c|c|c|c|}
\hline \multirow[b]{3}{*}{ Exposure* } & \multicolumn{6}{|l|}{ Lifelines } & \multicolumn{6}{|c|}{ Vlagtwedde-Vlaardingen } \\
\hline & \multicolumn{3}{|c|}{ Mild obstruction ( $\mathrm{FEV}_{1} / \mathrm{FVC}<70 \%$ ) } & \multicolumn{3}{|c|}{ Moderate/severe obstructiont } & \multicolumn{3}{|c|}{ Mild obstruction (FEV $1 / \mathrm{IVC}<70 \%$ ) } & \multicolumn{3}{|c|}{ Moderate/severe obstructiont } \\
\hline & OR $(95 \% \mathrm{Cl})$ & $N \neq$ & $p$ Value & OR $(95 \% \mathrm{Cl})$ & $\mathrm{N} \ddagger$ & $p$ Value & OR $(95 \% \mathrm{Cl})$ & $\mathrm{N} \ddagger$ & $p$ Value & OR $(95 \% \mathrm{Cl})$ & $\mathrm{N} \ddagger$ & p Value \\
\hline \multicolumn{13}{|l|}{ VGDF } \\
\hline Non-exposed & Ref & 917 & & Ref & 233 & & Ref & 196 & & Ref & 76 & \\
\hline Low & $1.08(0.96$ to 1.22$)$ & 578 & 0.199 & $1.05(0.84$ to 1.31$)$ & 145 & 0.662 & $1.22(0.95$ to 1.59$)$ & 167 & 0.124 & $1.82(1.27$ to 2.60$)$ & 89 & 0.001 \\
\hline High & $1.41(1.16$ to 1.70$)$ & 259 & $<0.001$ & 1.39 (1.00 to 1.92$)$ & 80 & 0.047 & $1.29(0.95$ to 1.74$)$ & 276 & 0.101 & 1.85 (1.23 to 2.79$)$ & 149 & 0.003 \\
\hline \multicolumn{13}{|l|}{ Gases/fumes } \\
\hline Non-exposed & Ref & 985 & & Ref & 251 & & Ref & 227 & & Ref & 97 & \\
\hline Low & $1.10(0.98$ to 1.24$)$ & 631 & 0.116 & $1.03(0.83$ to 1.28$)$ & 164 & 0.787 & 1.11 (0.87 to 1.42$)$ & 334 & 0.401 & 1.45 (1.04 to 2.01$)$ & 182 & 0.028 \\
\hline High & $1.44(1.16$ to 1.80$)$ & 138 & 0.001 & 1.47 (1.02 to 2.11$)$ & 43 & 0.039 & $1.32(0.92$ to 1.89$)$ & 78 & 0.130 & 1.55 (0.95 to 2.53$)$ & 35 & 0.081 \\
\hline \multicolumn{13}{|l|}{ Mineral dust } \\
\hline Non-exposed & Ref & 1317 & & Ref & 328 & & Ref & 348 & & Ref & 165 & \\
\hline Low & 1.19 (1.03 to 1.37$)$ & 331 & 0.018 & $1.22(0.95$ to 1.56$)$ & 91 & 0.128 & 1.16 (0.87 to 1.54$)$ & 104 & 0.318 & $1.29(0.88$ to 1.90$)$ & 50 & 0.199 \\
\hline High & 1.46 (1.11 to 1.92$)$ & 106 & 0.007 & 1.76 (1.15 to 2.72$)$ & 39 & 0.010 & 1.10 (0.76 to 1.58$)$ & 187 & 0.619 & 0.99 (0.61 to 1.61$)$ & 99 & 0.972 \\
\hline \multicolumn{13}{|l|}{ Biological dust } \\
\hline Non-exposed & Ref & 1196 & & Ref & 314 & & Ref & 324 & & Ref & 141 & \\
\hline Low & 1.04 (0.92 to 1.18$)$ & 481 & 0.502 & 0.99 (0.79 to 1.24$)$ & 121 & 0.916 & 1.34 (1.04 to 1.73$)$ & 243 & 0.022 & 1.74 (1.24 to 2.43$)$ & 137 & 0.001 \\
\hline High & 0.91 (0.66 to 1.25$)$ & 77 & 0.550 & 0.77 (0.45 to 1.33$)$ & 23 & 0.345 & 1.25 (0.84 to 1.84$)$ & 72 & 0.271 & 1.54 (0.92 to 2.55$)$ & 36 & 0.098 \\
\hline \multicolumn{13}{|l|}{ All pesticides } \\
\hline Non-exposed & Ref & 1667 & & Ref & 428 & & Ref & 478 & & Ref & 227 & \\
\hline Low & $0.83(0.60$ to 1.14$)$ & 59 & 0.241 & 1.15 (0.69 to 1.93$)$ & 20 & 0.595 & $1.33(0.87$ to 2.01$)$ & 52 & 0.185 & $1.08(0.61$ to 1.90$)$ & 23 & 0.791 \\
\hline High & $1.28(0.79$ to 2.09$)$ & 28 & 0.322 & $1.95(0.92$ to 4.13$)$ & 10 & 0.083 & $1.48(1.04$ to 2.10$)$ & 109 & 0.029 & 1.78 (1.14 to 2.79$)$ & 64 & 0.011 \\
\hline \multicolumn{13}{|l|}{ Herbicides } \\
\hline Non-exposed & Ref & 1711 & & Ref & 444 & & Ref & 511 & & Ref & 241 & \\
\hline Low & $1.04(0.65$ to 1.67$)$ & 27 & 0.872 & $1.11(0.51$ to 2.45$)$ & 8 & 0.791 & 1.29 (0.85 to 1.98$)$ & 50 & 0.235 & $1.60(0.93$ to 2.76$)$ & 28 & 0.090 \\
\hline High & 2.11 (1.03 to 4.30$)$ & 16 & 0.040 & 3.56 (1.28 to 9.88$)$ & 6 & 0.015 & 1.36 (0.93 to 2.00$)$ & 78 & 0.112 & 1.66 (1.02 to 2.69$)$ & 45 & 0.040 \\
\hline \multicolumn{13}{|l|}{ Insecticides } \\
\hline Non-exposed & Ref & 1675 & & Ref & 430 & & Ref & 494 & & Ref & 237 & \\
\hline Low & 0.81 (0.58 to 1.15$)$ & 51 & 0.241 & 1.21 (0.70 to 2.09$)$ & 18 & 0.497 & $1.04(0.64 ; 1.70)$ & 36 & 0.867 & 0.66 (0.33 to 1.33$)$ & 13 & 0.249 \\
\hline High & $1.32(0.81$ to 2.16$)$ & 28 & 0.268 & 2.05 (0.96 to 4.35$)$ & 10 & 0.062 & 1.39 (0.98 to 1.98$)$ & 109 & 0.067 & 1.62 (1.04 to 2.52$)$ & 64 & 0.033 \\
\hline
\end{tabular}

Associations between associations are depicted in bold.

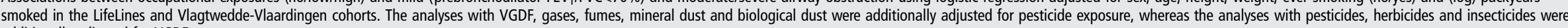
additionally adjusted for VGDF exposure.

"Occupational exposures (no/low/high) were estimated based on job title and function using the ALOHA+ job exposure matrix. Non-exposed subjects were assigned as reference category (Ref). or prebronchodilator $\mathrm{FEV}_{1} / \mathrm{FVC} \geq 70 \%$ and $\mathrm{FEV}_{1}<80 \%$ predicted were excluded from this analysis (LifeLines $\mathrm{n}=1517(13 \%)$ and Vlagtwedde-Vlaardingen $\mathrm{n}=436(18 \%)$ ). For Vlagtwedde-Vlaardingen: $\mathrm{FEV} / \mathrm{IVC}$ instead of $\mathrm{FEV} / \mathrm{FVC}_{1}$

or prebronchodilator $\mathrm{FEV} / / \mathrm{FV} \geq 70 \%$ and
¥Number of subjects with obstruction.

VGDF, vapours, gases, dust and fumes. 
and smoking. Second, findings were verified in a second independent cohort. Another strength of the study was the use of the ALOHA+ JEM, which was built specifically for use in general population studies. In general, JEM-based exposure estimates are less likely to be affected by recall bias and differential misclassification of exposure compared with self-reported exposures. $^{25}{ }^{26}$ Finally, we have adjusted our models to overcome possible confounding resulting from co-exposure to pesticides/ VGDF. Unadjusted models (not shown) yielded considerably stronger associations, suggesting that workers in occupations exposed to both VGDF and pesticides might be at higher risk than suggested by the adjusted associations that were shown in the current article.

\section{CONCLUSIONS}

To conclude, we showed large and clinically relevant losses of lung function level signified by airway obstruction in individuals occupationally exposed to VGDF and pesticides within two general populations. Interventions to reduce exposure levels at the workplace could therefore significantly contribute to lowering the global burden associated with COPD.

Acknowledgements We thank Rob Bieringa, Joost Keers, René Oostergo, Rosalie Visser and Judith Vonk for their work related to data collection and validation in the Lifelines cohort study. We are grateful to the study participants, the staff from the LifeLines cohort study and Medical Biobank Northern Netherlands and the participating general practitioners and pharmacists. We thank Jan Schouten for his work related to data collection and validation in the Vlagtwedde-Vlaardingen cohort. We thank Maartje Brouwer for providing additional information regarding pesticide use in the Northern Dutch Provinces.

Collaborators LifeLines cohort study: BZ Alizadeh: Department of Epidemiology, University of Groningen, University Medical Center Groningen, Groningen, The Netherlands; RA de Boer: Department of Cardiology, University of Groningen, University Medical Center Groningen, Groningen, The Netherlands; H M Boezen: Department of Epidemiology, University of Groningen, University Medical Center Groningen, Groningen, The Netherlands; M Bruinenberg: the LifeLines cohort study, University of Groningen, University Medical Center Groningen, Groningen, The Netherlands; L Franke: Department of Genetics, University of Groningen, University Medical Center Groningen, Groningen, The Netherlands; P van der Harst: Department of Cardiology, University of Groningen, University Medical Center Groningen, Groningen, The Netherlands; HL Hillege: Department of Epidemiology, University of Groningen, University Medical Center Groningen, Groningen, The Netherlands; Department of Cardiology, University of Groningen, University Medical Center Groningen, Groningen, The Netherlands; MM van der Klauw: Department of Endocrinology, University of Groningen, University Medical Center Groningen, Groningen, The Netherlands; G Navis: Department of Internal Medicine, Division of Nephrology, University of Groningen, University Medical Center Groningen, Groningen, The Netherlands; J Ormel: Department of Psychiatry, University of Groningen, University Medical Center Groningen, Interdisciplinary Center of Psychopathology of Emotion Regulation (ICPE), Groningen, The Netherlands; DS Postma: Department of Pulmonology, University of Groningen, University Medical Center Groningen, Groningen The Netherlands; JGM Rosmalen: Department of Psychiatry, University of Groningen, University Medical Center Groningen, Interdisciplinary Center of Psychopathology of Emotion Regulation (ICPE), Groningen, The Netherlands; JP Slaets: University of Groningen, University Medical Center Groningen, University Center for Geriatric Medicine, Groningen, The Netherlands; H Snieder: Department of Epidemiology, University of Groningen, University Medical Center Groningen, Groningen, The Netherlands; RP Stolk: Department of Epidemiology, University of Groningen, University Medical Center Groningen, Groningen, The Netherlands; BHR Wolffenbuttel: Department of Endocrinology, University of Groningen, University Medical Center Groningen, Groningen, The Netherlands; C Wijmenga: Department of Genetics, University of Groningen, University Medical Center Groningen, Groningen, The Netherlands.

Contributors $\mathrm{KdJ}$ participated in the study design, analysis and interpretation of the data and drafting of the manuscript, tables and figures. HMB, DSP and JMV obtained funding, determined the study design, participated in the analysis and interpretation of data and critically supervised writing of the manuscript. $\mathrm{HK}$ and RV designed and provided the ALOHA+ JEM and participated in writing of the manuscript. All authors approved the final version of the manuscript.

Funding The LifeLines cohort study was supported by the Dutch Ministry of Health, Welfare and Sport, the Ministry of Economic Affairs, Agriculture and Innovation, The Province of Groningen, the European Union (Regional Development Fund), the Northern Netherlands Provinces (SNN), the Netherlands Organization for Scientific Research (NWO), University Medical Center Groningen (UMCG), University of Groningen, de Nierstichting (the Dutch Kidney Foundation) and the Diabetes Fonds (the Diabetic Foundation). The Vlagtwedde-Vlaardingen cohort was supported by the Ministry of Health and Environmental Hygiene of The Netherlands and Netherlands Asthma Fund Grant Number 187. KdJ was funded by research school GUIDE, University of Groningen, University Medical Center Groningen. The sponsors of this study had no role in the design of this study, data collection, analysis and interpretation or in writing and submitting of the manuscript.

Competing interests All authors have completed the ICMJE uniform disclosure. The University of Groningen has received money for DSP regarding an unrestricted educational grant for research from AstraZeneca and GSK. Fees for consultancies were given to the University of Groningen by AstraZeneca, Boehringer Ingelheim, Chiesi, GSK, Nycomed and TEVA. HK has done consultancy for the Norwegian government. KdJ, HMB, RV and JMV do not have competing interests.

Patient consent Obtained.

Ethics approval University Medical Center Groningen Medical Ethical Commission (METC).

Provenance and peer review Not commissioned; externally peer reviewed.

\section{REFERENCES}

1 World Health Organization. Chronic obstructive pulmonary disease (COPD)—fact sheet. http://www.who.int/mediacentre/factsheets/fs315/en/index.html (accessed 16 Apr 2013).

2 National Heart Lung and Blood Institute. Morbidity and mortality. 2009 chart book on cardiovascular, lung and blood diseases. National Institutes of Health, 2009.

3 Vos T, Flaxman AD, Naghavi M, et al. Years lived with disability (YLDs) for 1160 sequelae of 289 diseases and injuries 1990-2010: a systematic analysis for the global burden of disease study 2010. Lancet 2012;380:2163-96.

4 World Health Organization. Chronic respiratory diseases. http://www.who.int/ respiratory/en/ (accessed 10 Apr 2013)

5 Barnes P, Kleinert S. COPD-a neglected disease. Lancet 2004;364:564-5.

6 Balmes J, Becklake M, Blanc $\mathrm{P}$, et al. American thoracic society statement: occupational contribution to the burden of airway disease. Am I Respir Crit Care Med 2003;167:787-97.

7 Hnizdo E, Sullivan PA, Bang KM, et al. Association between chronic obstructive pulmonary disease and employment by industry and occupation in the US population: a study of data from the third national health and nutrition examination survey. Am J Epidemio/ 2002;156:738-46.

8 Matheson MC, Benke G, Raven J, et al. Biological dust exposure in the workplace is a risk factor for chronic obstructive pulmonary disease. Thorax 2005; 60:645-51

9 Blanc PD, Iribarren C, Trupin L, et al. Occupational exposures and the risk of COPD: dusty trades revisited. Thorax 2009:64:6-12.

10 Trupin L, Earnest G, San Pedro M, et al. The occupational burden of chronic obstructive pulmonary disease. Eur Respir J 2003;22:462-9.

11 Mehta A, Miedinger D, Keidel D, et al. Occupational exposure to dusts, gases and fumes and incidence of COPD in SAPALDIA. Am I Respir Crit Care Med 2012:185:1292-300.

12 International Labour Office. Global employment trends 2012. Geneva: International Labour Organization; 2012, Report No: ISBN 978-92-2-124924-5.

13 World Health Organization. Public health impact of pesticides used in agriculture. Geneva: World Health Organization; 1990, Report No: ISBN 92-4-156139-4.

14 Stolk R, Rosmalen JGM, Postma D, et al. Universal risk factors for multifactorial diseases: LifeLines: a three generation population-based study. Eur J Epidemiol 2008;23:67-74

15 International Labour Organization. The revised international standard classification of occupations (ISCO-88). Geneva: International Labour Organization, 1990.

16 Quanjer PH, Tammeling GJ, Cotes JE, et al. Lung volumes and forced ventilatory flows. Report working party standardization of lung function tests, European community for steel and coal. Official statement of the European respiratory society. Eur Respir J Supplement 1993;16:5-40.

17 Sunyer J, Kogevinas $\mathrm{M}$, Kromhout $\mathrm{H}$, et al. Pulmonary ventilatory defects and occupational exposures in a population-based study in Spain. Am J Respir Crit Care Med 1998;157:512-17.

18 Zock JP, Sunyer J, Kogevinas M, et al. Occupation, chronic bronchitis, and lung function in young adults. An international study. Am J Respir Crit Care Med 2001:163:1572-7.

19 Hoppin J, Valcin $\mathrm{M}$, Henneberger $\mathrm{P}$, et al. Pesticide use and chronic bronchitis among farmers in the agricultural health study. Am J Ind Med 2007;50:969-79.

20 Valcin $M$, Henneberger $P$, Kullman $G$, et al. Chronic bronchitis among nonsmoking farm women in the agricultural health study. J Occup Environ Med 2007:49:574-83. 
21 Peiris-John RJ, Ruberu DK, Wickremasinghe AR, et al. Low-level exposure to organophosphate pesticides leads to restrictive lung dysfunction. Respir Med 2005:99:1319-24.

22 Fieten $\mathrm{K}$, Kromhout $\mathrm{H}$, Heederik $\mathrm{D}$, et al. Pesticide exposure and respiratory health of indigenous women in Costa Rica. Am J Epidemiol 2009;169:1500-6.

23 Castro-Gutiérrez N, McConnell R, Andersson K, et al. Respiratory symptoms, spirometry and chronic occupational Paraquat exposure. Scand J Work Environ Health 1997;23:421-7.
24 Schenker M, Stoecklin M, Lee K, et al. Pulmonary function and exercise-associated changes with chronic low-level paraquat exposure. Am J Respir Crit Care Med 2004;170:773-9.

25 Mannetje $A$, Kromhout $H$. The use of occupation and industry classifications in general population studies. Int J Epidemiol 2003:32:419-28.

26 Kromhout $H$, Vermeulen R. Application of job-exposure matrices in studies of the general population: some clues to their performance. Eur Respir Rev 2001;11:80-90. 